\title{
Risk of prostate cancer in a population-based cohort of men with coeliac disease
}

\author{
JF Ludvigsson*,1,2, K Fall ${ }^{3,4}$ and S Montgomery ${ }^{2,3,5}$ \\ 'Department of Paediatrics, Örebro University Hospital, Örebro 701 85, Sweden; ${ }^{2}$ Clinical Epidemiology Unit, Department of Medicine, Karolinska \\ Institutet, Stockholm 171 76, Sweden; ${ }^{3}$ Clinical Epidemiology and Biostatistics Unit, Örebro University Hospital, Örebro University, Örebro 70185 , \\ Sweden; ${ }^{4}$ Department of Epidemiology, Harvard School of Public Health, Boston, MA 02I I 5, US; ${ }^{5}$ Department of Primary Care and Public Health, \\ Charing Cross Hospital, Imperial College, London W6 8RF, UK
}

BACKGROUND: Prostate cancer (PC) is a leading cause of fatal cancer in men in developed countries. Coeliac disease (CD) has previously been linked to a raised cancer risk, and changes in some exposures following a CD diagnosis might hypothetically raise PC risk.

METHODS: We identified 10995 patients with CD who had undergone a small intestinal biopsy in 1969-2007. Statistics Sweden then identified 54233 age-matched male reference individuals from the general population. PC data were obtained from the Swedish Cancer Register. Hazard ratios (HRs) for PC were estimated using Cox regression analysis.

RESULTS: During follow-up, 185 individuals with CD (expected $n=200$ ) had an incident diagnosis of PC. This corresponds to a HR of 0.92 (0.79- I.08) (with 95\% confidence interval) and an absolute risk reduction of 15/100 000 person-years among those with CD. An increased risk was not observed even when identification of PC began 5 years after biopsy.

CONCLUSION: Our conclusion is that a CD diagnosis does not represent an increased risk for PC. British Journal of Cancer (2012) 1 06, 217-221. doi:I0.1038/bjc.201 I.536 www.bjcancer.com

Published online I December 20 I

(C) 2012 Cancer Research UK

Keywords: coeliac disease; cohort study; inflammation; prostate cancer

Prostate cancer (PC) is one of the leading causes of cancer mortality in men in industrialised countries (Ferlay et al, 2010). Established risk-factors for PC include increasing age, ethnic origin, and hereditary/familial factors. Although the great variability in incidence across different parts of the world can be attributed largely to differences in diagnostic intensity, the over 10 -fold variation in mortality rates between low-risk countries in Asia and high-risk countries, such as Sweden (Ferlay et al, 2010), suggests that environmental factors, such as diet, may account for some of the observed variation (Shimizu et al, 1991; Hsing and Devesa, 2001).

Coeliac disease (CD) is an immune-mediated disease that occurs in $1 \%$ of the Western population (Dube et al, 2005). It is characterised by small intestinal inflammation and villous atrophy (VA) (Ludvigsson and Green, 2011). The only available treatment consists of a gluten-free diet where the individual avoids wheat, barley, and rye (Kupper, 2005), whereas consumption of oats is safe for patients with CD (Janatuinen et al, 1995).

Earlier research has shown a relative risk for PC in CD of around 1, with two studies suggesting a lower risk of PC (England: standardised incidence ratio $=0.67 ; 95 \%$ confidence interval $(\mathrm{CI})=$ $0.18-1.73$ ) (Goldacre et al, 2008) (Sweden: $0.7 ; 95 \% \mathrm{CI}=0.4-1.2$ ) (Askling et al, 2002), and one study suggesting a positive association between positive endomysial antibodies ('gluten sensitivity')

*Correspondence: Dr JF Ludvigsson; E-mail: jonasludvigsson@yahoo.com Received 6 September 2011; revised 31 October 2011; accepted 9 November 20 I ; published online I December 20 I | and PC (Northern Ireland: 1.78; 95\% CI $=0.00-4.24$ ) (Anderson et al, 2007). All of these studies were, however, based on $<20$ cases of PC. Additionally, there are single case-reports of PC in CD (Green et al, 2003; Card et al, 2004), but with no relative risks reported.

An association between $\mathrm{CD}$ and PC could potentially be mediated by several factors including dietary changes following diagnosis, as patients with $\mathrm{CD}$ are prescribed a gluten-free diet, which includes low intake of rye, wheat, barley, and refined grain. Dietary change could potentially influence PC risk, although the link between intake of whole grains and PC is unclear. Two small intervention studies among PC patients have reported associations between increased rye intake and tumour growth in terms of reduced PSA-levels and increased apoptosis (Bylund et al, 2003; Landberg et al, 2010), while observational studies of whole grain consumption and PC risk show inconsistent results (Chatenoud et al, 1998; Lewis et al, 2009; Egeberg et al, 2011).

In this study, we tested the hypothesis that men with a diagnosis of CD have a higher risk of PC. This was tested using longitudinal Swedish register data for 10995 men with CD and 54233 age-matched men in the comparison cohort.

\section{MATERIALS AND METHODS}

We used national Swedish data from biopsy reports to identify patients with $\mathrm{CD}$. These data were linked to the Swedish Cancer Register in order to examine the risk of PC. 
PC

PC was defined according to the International Classification of Disease (ICD) 7-code 177 in the Swedish Cancer Register (equivalent to ICD-8 and 9: 185 and ICD-10: C61).

\section{CD}

From October 2006 to February 2008, data from small intestinal biopsy reports were collected from each of Sweden's 28 pathology departments. The biopsies were performed between 1969 and 2008. $\mathrm{CD}$ was defined as having a biopsy report with VA (equivalent to Marsh grade 3; see Supplementary Appendix) (Marsh, 1992). We did not require positive serology for a CD diagnosis, but an earlier validation study found that among patients with available $C D$ serology data at the time of biopsy, $88 \%$ had positive serology (Ludvigsson et al, 2009a). The validation study also found that $95 \%$ of patients with VA had CD according to medial records $(n=108 / 114)$ and that $79 \%$ of patients had gastrointestinal symptoms at the time of biopsy.

Local IT personnel conducted the searches for relevant biopsy reports and data on the arrival dates of the biopsies, personal identity number (Ludvigsson et al, 2009c), morphology according to the Swedish SnoMed classification codes (for a translation into international classification systems, see Supplementary Appendix), and topography (duodenum/jejunum). These data were then delivered to the researchers. The CD cohort used here was based on the 29096 individuals with CD and was examined for overall mortality in a recent paper by our group (Ludvigsson et al, 2009b). The number of age- and sex-matched controls (identified by the government agency statistics) individually matched with patients with CD in that study was 144522 .

The CD study sample was then restricted to 11091 male CD patients (18005 females excluded) (Ludvigsson et al, 2009b). We then excluded individuals with CD who had a biopsy after 31 December $2007(n=5)$ because our follow-up ended on 31 December 2007 (cancer data available until this date), individuals with a diagnosis of PC before CD diagnosis $(n=90)$. Finally, there was left one individual with $C D$ whose matched comparators had been excluded for any of the above reasons.

Of the initial 144522 controls, 55300 were males (89222 females were excluded). We also excluded controls that entered the study after 31 December $2007(n=25)$, those with a diagnosis of PC before CD diagnosis $(n=480)$, and controls whose matched index individuals with $\mathrm{CD}$ had been excluded at some stage $(n=562)$.

The final sample consisted of 10995 men with CD and 54233 in the age-matched male comparison cohort.

\section{Statistics}

Cox regression was used to estimate relative risks. In our statistical model, we used internal stratification for age at the time of the first biopsy (and corresponding age in reference individuals), calendar period, and county. Our analysis therefore took into account the influence of age, calendar period, and county (similar to the effect of use of risk-sets in conditional logistic regression). Follow-up time started on the date of the first biopsy with VA and on the corresponding date in matched reference individuals. It ended with a diagnosis of PC, death, emigration, or on 31 December 2007, whichever came first. In reference individuals, follow-up could also end if the individual underwent a small intestinal biopsy. We used log-minus-log curves to test the proportional hazards assumption (Figure in Supplementary Appendix showing that this condition was fulfilled). We also evaluated the risk of PC stratified by followup time ( $<1$ year, 1 to $<5$ years, and $\geqslant 5$ years), sex, age at CD diagnosis $(0-19,20-39,40-59$, and $\geqslant 60$ years at first biopsy), and calendar period of the first biopsy $(-1989,1990-1999$, and 2000 until present). Death due to PC (based on underlying cause of death according to death certificates) was used as an alternative outcome in a subanalysis in an attempt to identify a more aggressive PC phenotype. Incidence rates were calculated using the number of first PC events divided by the number of person-years at risk. The expected number of cases was derived from the observed number of cases divided by the hazard ratio (HR). In this way, the expected number of cases is based on the age and sex distribution of the CD cohort.

We identified individuals with type 1 diabetes using the Swedish Hospital Discharge Register (see Supplementary Appendix for ICD codes) (Ludvigsson et al, 2011). Type 1 diabetes is associated with CD (Bao et al, 1999; Smyth et al, 2008), but inversely associated with PC, so concomitant type 1 diabetes could therefore potentially hide a positive association between $\mathrm{CD}$ and PC. A subanalysis excluded all individuals with a diagnosis of type 1 diabetes, irrespective of when the diagnosis was made.

In another subanalysis, we adjusted for education using seven a priori educational categories determined by Statistics Sweden ( $<9$ years, $9-10$ years, $\leqslant 2$ years of high school, $\geqslant 3$ years of high school, $<3$ years of college/university, $\geqslant 3$ years of college, and postgraduate studies). In a third subanalysis, we adjusted for country of birth (Nordic and non-Nordic countries).

Statistical significance defined as $95 \%$ CI for risk estimates not including 1.0. SPSS 18.0 software (SPSS Inc., Chicago, IL, USA) was used for the statistical analysis.

\section{RESULTS}

\section{Background data}

The majority of the participants with CD had a biopsy from 1990 onwards and entered the study at this time, as did the matched comparison cohort. The median age at diagnosis of PC was 71 years in men with $\mathrm{CD}$ and 72 years in the comparison cohort. Other characteristics of the study participants are listed in Table 1. Some $3.8 \%$ of the individuals with $\mathrm{CD}$ but only $0.4 \%$ of the matched controls had a diagnosis of type 1 diabetes before the end of follow-up $\left(P<0.001, \chi^{2}\right.$-test $)$.

\section{$\mathrm{CD}$ and subsequent PC}

During follow-up, there were 185 diagnoses of PC (expected $n=200)$, corresponding to a HR of $0.92(95 \% \mathrm{CI}=0.79-1.08)$ (Table 2). The risk estimate did not change notably when we excluded individuals with a diagnosis of type 1 diabetes $(0.93 ; 0.79-1.09)$. Nor did it change notably when we adjusted for country of birth $(0.92 ; 0.78-1.07)$ or education $(0.93 ; 0.78-1.12)$.

When we excluded the first year of follow-up to minimise the risk of surveillance bias, the HR was little changed (0.89; 0.75 -1.06). After 5 years of follow-up, giving sufficient time for an influence of the diet, the HR for PC in CD was 1.00 (Table 2).

The differences in PC risk by age at CD diagnosis were not statistically significant ( $P$-value for interaction: 0.197) (Table 3 ). There were no notable differences in risk estimates for PC by calendar period ( $P$-value for interaction: 0.926$)$.

When death due to $\mathrm{PC}$, indicating more aggressive disease, was used as an alternative outcome (with 21 deaths among CD patients and an expected of 36), the HR for the association of CD with PCrelated death remained below 1.00 (data not shown).

\section{DISCUSSION}

This study found no association between $\mathrm{CD}$ and PC using longitudinal data. It is one of the first large-scale studies of this subject and it used histology from intestinal biopsies to identify CD reliably. Our findings are consistent with the two general population-based studies from England (Goldacre et al, 2008) and 
Sweden (Askling et al, 2002), although this study had substantially more statistical power to detect an association.

Although earlier studies on CD and PC have been based on as few as 2-14 positive events (Askling et al, 2002; Anderson et al, 2007; Goldacre et al, 2008), we observed 185 PC diagnoses in patients with CD during follow-up. The greater statistical power of our study allowed for stratification and greater precision.

CD patients in our cohort were ascertained through biopsy reports, so they are more likely to have typical CD characteristics than those identified through inpatient registers as this may signal comorbidity (Askling et al, 2002; Goldacre et al, 2008), because CD investigation does not require hospital care. Most adult gastroenterologists (96\%) and all paediatricians obtain biopsies from the majority of patients with suspected CD (over 90\%) to make the diagnosis. Therefore, diagnosis of $\mathrm{CD}$ among our study population is highly reliable. Small intestinal biopsies with VA have high specificity for CD. When two independent researchers examined more than 1500 biopsy reports with VA or inflammation, $<0.3 \%$ of patients suffered from inflammatory bowel disease, which was the most common comorbidity (other than CD) (Ludvigsson et al, 2009a). Patients with CD are at increased risk of comorbid type 1 diabetes. We performed an analysis where all the individuals with a diagnosis of type 1 diabetes before the end of follow-up were excluded. This exclusion did not affect the risk estimates for PC.

Table I Characteristics of the study participants

\begin{tabular}{|c|c|c|}
\hline & $\begin{array}{l}\text { Matched } \\
\text { controls }\end{array}$ & $\begin{array}{l}\text { Patients } \\
\text { with CD }\end{array}$ \\
\hline Total & 54233 & 10995 \\
\hline \multicolumn{3}{|l|}{ Age and follow-up } \\
\hline $\begin{array}{l}\text { Age at study entry, years } \\
\text { (median, range) }\end{array}$ & $34 ; 0-95$ & $35 ; 0-95$ \\
\hline Age $0-19(\%)$ & $21734(40.1)$ & $4356(39.6)$ \\
\hline Age $20-39(\%)$ & $8216(15.1)$ & $1659(15.1)$ \\
\hline Age $40-59(\%)$ & $12946(23.9)$ & $2605(23.7)$ \\
\hline Age $\geqslant 60(\%)$ & | | 337 (20.9) & $2375(21.6)$ \\
\hline Entry year (median, range) & 1998; 1969-2007 & $1998 ; 1969-2007$ \\
\hline Follow-up, years (median, range) ${ }^{a}$ & 8; $0-39$ & $8 ; 0-37$ \\
\hline Follow-up, years $(\text { mean } \pm S D)^{\mathrm{a}}$ & $9.5 \pm 6.4$ & $9.3 \pm 6.4$ \\
\hline \multicolumn{3}{|l|}{ Calendar year } \\
\hline$-1989(\%)$ & $8101(14.9)$ & $1643(14.9)$ \\
\hline $1990-1999(\%)$ & $22824(42.1)$ & $4627(42.1)$ \\
\hline $2000-(\%)$ & $23308(43.0)$ & $4725(43.0)$ \\
\hline \multicolumn{3}{|l|}{ Covariates } \\
\hline Nordic country of birth $(\%)^{b}$ & $5|24|(94.5)$ & $10662(97.0)$ \\
\hline Type I diabetes (\%) & $208(0.4)$ & $418(3.8)$ \\
\hline
\end{tabular}

Abbreviation: $\mathrm{CD}=$ coeliac disease. ${ }^{\mathrm{a}}$ Follow-up time until diagnosis of prostate, death from other cause, emigration, or 31 December 2007. In reference individuals, follow-up could end if the patients underwent a small intestinal biopsy. 'bweden, Denmark. Finland, Norway, and Iceland.
One weakness of this study is the lack of individual data on dietary components or compliance to a gluten-free diet. Some aspects of dietary compliance could theoretically raise the risk of PC, although mucosal healing and less chronic inflammation might reduce the risk. In a validation study of 121 randomly selected individuals with VA, there were indications of low dietary compliance in $15 / 86$ individuals $(17,95 \% \mathrm{CI}=9-25 \%)$, thus with dietary compliance in $83 \%$ (Ludvigsson et al, 2009a). This study found no association between $\mathrm{CD}$ and $\mathrm{PC}(\mathrm{HR}=0.92)$.

As PC may have a prolonged natural history (Schmid et al, 1993), we also examined risk of PC according to time since diagnosis of $\mathrm{CD}$. Although there was no association between $\mathrm{CD}$ and PC in the first year beyond biopsy, or more than 5 years after biopsy, there was a statistically significant reduced risk of PC 1-5 years after CD diagnosis. We cannot rule out that there is a true decreased risk of PC in CD due to factors, such as lower body mass index (BMI) in patients with $\mathrm{CD}$ (Discacciati et al, 2011). In the first year after diagnosis, this may be masked by an increased ascertainment rate of PC as comorbid conditions are more likely to be detected during diagnosis or treatment. With time, the lower PC risk may not persist as mucosal healing results in increased BMI. It should be noted that the apparent reduced risk 1-5 years after $\mathrm{CD}$ diagnosis could represent a chance finding.

Although the total follow-up time for patients with $\mathrm{CD}$ in this study was 101000 person-years, we did not have enough follow-up to estimate the risk of PC in CD diagnosed in childhood. It has been suggested that an early diagnosis of $\mathrm{CD}$ in childhood may protect against certain cancers (Elfstrom et al, 2011), but as participants in this study tended to receive a later diagnosis, this putative protection against cancer could not have concealed a positive association. Other immune-mediated diseases, such as type 1 diabetes (Kasper et al, 2009; Shu et al, 2010), ulcerative colitis (Goldacre et al, 2008), Crohn's disease (Goldacre et al, 2008), and Wegener's granulomatosis have been inversely associated with PC (Knight et al, 2002). This study found no association between $\mathrm{CD}$ and PC.

Also, adolescence represents a critical window of prostate development, where diet (Andersson et al, 1995) and hormonal exposure (Barba et al, 2008) could be important. Although we could investigate participants with a CD diagnosis at younger ages, it is important to emphasise that there was no evidence of increased PC risk among men diagnosed with CD from age 40 years: this study would have been able to detect such a risk. This indicates that middle-aged men who receive a diagnosis of $\mathrm{CD}$ need not be concerned that the diagnosis, or dietary changes typically associated with it, could increase their risk of PC.

Another potential weakness is our lack of data on BMI. High BMI has been inversely associated with CD (Olen et al, 2009), but positively associated with PC (Moller et al, 1994), although most prospective studies do not support this association (Rodriguez et al, 2007; Wright et al, 2007). Neither did we have any data on smoking. Smoking may increase the risk of PC (Plaskon et al, 2003). Although several studies have indicated an inverse relationship between smoking and CD (Vazquez et al, 2001; Austin et al, 2002),

Table 2 Risk of prostate cancer by follow-up time

\begin{tabular}{|c|c|c|c|c|c|c|c|c|}
\hline Follow-up & $\begin{array}{l}\text { Observed } \\
\text { events }\end{array}$ & $\begin{array}{l}\text { Expected } \\
\text { events }\end{array}$ & HR & $95 \% \mathrm{Cl}$ & $P$-value & $\begin{array}{c}\text { Absolute } \\
\text { risk/100000 PYAR }\end{array}$ & $\begin{array}{c}\text { Excess } \\
\text { risk//00000 PYAR }\end{array}$ & $\begin{array}{c}\text { Attributable } \\
\text { percentage }\end{array}$ \\
\hline All & 185 & 200 & 0.92 & $0.79-1.08$ & 0.336 & 182 & -15 & -8 \\
\hline $5+$ & 115 & 115 & 1.00 & $0.82-1.23$ & 0.985 & 209 & 0 & 0 \\
\hline
\end{tabular}

Abbreviations: $\mathrm{Cl}=$ confidence interval; $\mathrm{HR}=$ hazard ratio; PYAR = person-years at risk. Reference is general population comparator cohort. The attributable percentage was calculated as $(I-I / H R)$. 
Table 3 Risk of prostate cancer (subgroup analyses)

\begin{tabular}{|c|c|c|c|c|c|c|c|c|}
\hline Subgroup & $\begin{array}{l}\text { Observed } \\
\text { events }\end{array}$ & $\begin{array}{l}\text { Expected } \\
\text { events }\end{array}$ & HR & HR; 95\% Cl & $P$-value & $\begin{array}{c}\text { Absolute } \\
\text { risk/100000 PYAR }\end{array}$ & $\begin{array}{c}\text { Excess } \\
\text { risk// } 00000 \text { PYAR }\end{array}$ & $\begin{array}{c}\text { Attributable } \\
\text { percentage }\end{array}$ \\
\hline \multicolumn{9}{|l|}{ Age (years) } \\
\hline $40-59$ & 71 & 69 & 1.03 & $0.79-1.33$ & 0.841 & 285 & 7 & 3 \\
\hline $60+$ & 111 & 131 & 0.85 & $0.69-1.04$ & 0.118 & 744 & -133 & -18 \\
\hline $1990-1999$ & 95 & 103 & 0.92 & $0.74-1.15$ & 0.464 & 181 & -16 & -9 \\
\hline $2000-$ & 41 & 46 & 0.89 & $0.64-1.24$ & 0.504 & 211 & -25 & -12 \\
\hline
\end{tabular}

Abbreviations: $\mathrm{Cl}=$ confidence interval; $\mathrm{HR}=$ hazard ratio; PYAR = person-years at risk. Reference is general population comparator cohort. The attributable percentage was calculated as $(\mathrm{I}-\mathrm{I} / \mathrm{HR})$.

a recent study by our group found a nonsignificantly increased risk for later CD in smokers (adjusted Odds ratio $=1.25 ; 95 \% \mathrm{CI}=$ 0.94-1.67) (Ludvigsson et al, 2005). Although unlikely, we cannot rule out the possibility that lower BMI and a lack of smoking among individuals with CD may have hidden a modest association between CD and PC.

PSA-testing has, since it was introduced during the 90s, resulted in a rising overdiagnosis of PC (i.e., detection of nonlethal pseudotumours) and it is becoming increasingly important to separate clinically significant PC from indolent disease in aetiological studies. The Swedish Cancer Registry covers essentially all incident PCs, but lacks information on tumour stage and Gleason grade. Although PSA-screening is less common in Sweden than in the United States and many other Western countries, around $40 \%$ of the cases were diagnosed with screening-detected PC in Sweden during the latter part of the study period (National Prostate Cancer Register, http://www.roc.se/prostata.asp). We tackled this through a subanalysis that used death due to PC as the outcome to identify more aggressive disease. Again, there was no raised risk associated with a CD diagnosis.

In conclusion, patients with $\mathrm{CD}$ seem to be at no increased risk of PC.

\section{Ethical approval}

This project (2006/633-31/4) was approved by the Research Ethics Committee of the Karolinska Institute, Sweden on 14 June 2006.

\section{REFERENCES}

Anderson LA, McMillan SA, Watson RG, Monaghan P, Gavin AT, Fox C, Murray LJ (2007) Malignancy and mortality in a population-based cohort of patients with coeliac disease or 'gluten sensitivity'. World $J$ Gastroenterol 13(1): $146-151$

Andersson SO, Baron J, Wolk A, Lindgren C, Bergstrom R, Adami HO (1995) Early life risk factors for prostate cancer: a population-based case-control study in Sweden. Cancer Epidemiol Biomarkers Prev 4(3): $187-192$

Askling J, Linet M, Gridley G, Halstensen TS, Ekstrom K, Ekbom A (2002) Cancer incidence in a population-based cohort of individuals hospitalized with celiac disease or dermatitis herpetiformis. Gastroenterology 123(5): $1428-1435$

Austin AS, Logan RF, Thomason K, Holmes GK (2002) Cigarette smoking and adult coeliac disease. Scand J Gastroenterol 37(8): 978-982

Bao F, Yu L, Babu S, Wang T, Hoffenberg EJ, Rewers M, Eisenbarth GS (1999) One third of HLA DQ2 homozygous patients with type 1 diabetes express celiac disease-associated transglutaminase autoantibodies. J Autoimmun 13(1): $143-148$

\section{ACKNOWLEDGEMENTS}

JFL was supported by a grant from the Örebro University Hospital while writing this article. This project was supported by grants from the Swedish Society of Medicine, the Swedish Research CouncilMedicine (522-2A09-195), the Sven Jerring Foundation, the Örebro Society of Medicine, the Karolinska Institutet, the Clas Groschinsky Foundation, the Juhlin Foundation, the Majblomman Foundation, Uppsala-Örebro Regional Research Council, and the Swedish Coeliac Society. SM was supported by funding from the Economic and Social Research Council grant RES - 596-28-0001 to the International Centre for Life-Course Studies. Guarantor JFL had full access to all the data in the study and takes responsibility for the integrity of the data and the accuracy of the data analyses.

\section{Disclaimer}

Independence (role of the sponsors): None of the funders had any role in the design and conduct of the study, collection, management, analysis, and interpretation of the data, and preparation, review, or approval of the manuscript.

\section{Conflict of interest}

The authors declare no conflict of interest.

Supplementary Information accompanies the paper on British Journal of Cancer website (http://www.nature.com/bjc)

Barba M, , Terrenato I, , Schunemann HJ, Fuhrman B, Sperati F, Teter B, Gallucci M, D'Amato A, Muti P (2008) Indicators of sexual and somatic development and adolescent body size in relation to prostate cancer risk: results from a case-control study. Urology 72(1): 183-187

Bylund A, Lundin E, Zhang JX, Nordin A, Kaaks R, Stenman UH, Aman P, Adlercreutz H, Nilsson TK, Hallmans G, Bergh A, Stattin P (2003) Randomised controlled short-term intervention pilot study on rye bran bread in prostate cancer. Eur J Cancer Prev 12(5): 407-415

Card TR, West J, Holmes GK (2004) Risk of malignancy in diagnosed coeliac disease: a 24-year prospective, population-based, cohort study. Aliment Pharmacol Ther 20(7): 769-775

Chatenoud L, Tavani A, La Vecchia C, Jacobs Jr DR, Negri E, Levi F, Franceschi S (1998) Whole grain food intake and cancer risk. Int J Cancer 77(1): $24-28$

Discacciati A, Orsini N, Andersson SO, Andren O, Johansson JE, Wolk A (2011) Body mass index in early and middle-late adulthood and risk of localised, advanced and fatal prostate cancer: a population-based prospective study. $\mathrm{Br}$ J Cancer 105(7): $1061-1068$ 
Dube C, Rostom A, Sy R, Cranney A, Saloojee N, Garritty C, Sampson M, Zhang L, Yazdi F, Mamaladze V, Pan I, Macneil J, Mack D, Patel D, Moher D (2005) The prevalence of celiac disease in average-risk and atrisk Western European populations: a systematic review. Gastroenterology 128(4 Suppl 1): S57 - S67

Egeberg R, Olsen A, Christensen J, Johnsen NF, Loft S, Overvad K, Tjonneland A (2011) Intake of whole-grain products and risk of prostate cancer among men in the Danish Diet, Cancer and Health cohort study. Cancer Causes Control 22(8): 1133-1139

Elfstrom P, Granath F, Ekstrom Smedby K, Montgomery SM, Askling J, Ekbom A, Ludvigsson JF (2011) Risk of lymphoproliferative malignancy in relation to small intestinal histopathology among patients with celiac disease. J Natl Cancer Inst 103(5): 436-444

Ferlay J, Shin HR, Bray F, Forman D, Mathers C, Parkin DM (2010) Estimates of worldwide burden of cancer in 2008: GLOBOCAN 2008. Int $J$ Cancer 127(12): 2893-2917

Goldacre MJ, Wotton CJ, Yeates D, Seagroatt V, Jewell D (2008) Cancer in patients with ulcerative colitis, Crohn's disease and coeliac disease: record linkage study. Eur J Gastroenterol Hepatol 20(4): 297 - 304

Green PH, Fleischauer AT, Bhagat G, Goyal R, Jabri B, Neugut AI (2003) Risk of malignancy in patients with celiac disease. Am J Med 115(3): 191-195

Hsing AW, Devesa SS (2001) Trends and patterns of prostate cancer: what do they suggest? Epidemiol Rev 23(1): 3-13

Janatuinen EK, Pikkarainen PH, Kemppainen TA, Kosma VM, Jarvinen RM, Uusitupa MI, Julkunen RJ (1995) A comparison of diets with and without oats in adults with celiac disease [see comments]. $N$ Engl J Med 333(16): $1033-1037$

Kasper JS, Liu Y, Giovannucci E (2009) Diabetes mellitus and risk of prostate cancer in the health professionals follow-up study. Int J Cancer 124(6): $1398-1403$

Knight A, Askling J, Ekbom A (2002) Cancer incidence in a populationbased cohort of patients with Wegener's granulomatosis. Int J Cancer 100(1): $82-85$

Kupper C (2005) Dietary guidelines and implementation for celiac disease. Gastroenterology 128(4 Suppl 1): S121 - S127

Landberg R, Andersson SO, Zhang JX, Johansson JE, Stenman UH, Adlercreutz H, Kamal-Eldin A, Aman P, Hallmans G (2010) Rye whole grain and bran intake compared with refined wheat decreases urinary C-peptide, plasma insulin, and prostate specific antigen in men with prostate cancer. J Nutr 140(12): $2180-2186$

Lewis JE, Soler-Vila H, Clark PE, Kresty LA, Allen GO, Hu JJ (2009) Intake of plant foods and associated nutrients in prostate cancer risk. Nutr Cancer 61(2): 216-224

Ludvigsson JF, Andersson E, Ekbom A, Feychting M, Kim JL, Reuterwall C, Heurgren M, Otterblad Olausson P (2011) External review and validation of the Swedish national inpatient register. BMC Public Health 11(1): 450

Ludvigsson JF, Brandt L, Montgomery SM, Granath F, Ekbom A (2009a) Validation study of villous atrophy and small intestinal inflammation in Swedish biopsy registers. BMC Gastroenterol 9(1): 19
Ludvigsson JF, Green PH (2011) Clinical management of coeliac disease. $J$ Intern Med 269(6): 560-571

Ludvigsson JF, Montgomery SM, Ekbom A (2005) Smoking and celiac disease: a population-based cohort study. Clin Gastroenterol Hepatol 3(9): $869-874$

Ludvigsson JF, Montgomery SM, Ekbom A, Brandt L, Granath F (2009b) Small-intestinal histopathology and mortality risk in celiac disease. JAMA 302(11): 1171-1178

Ludvigsson JF, Otterblad-Olausson P, Pettersson BU, Ekbom A (2009c) The Swedish personal identity number: possibilities and pitfalls in healthcare and medical research. Eur J Epidemiol 24(11): 659-667

Marsh MN (1992) Gluten, major histocompatibility complex, and the small intestine. a molecular and immunobiologic approach to the spectrum of gluten sensitivity ('celiac sprue'). Gastroenterology 102(1): $330-354$

Moller H, Mellemgaard A, Lindvig K, Olsen JH (1994) Obesity and cancer risk: a Danish record-linkage study. Eur J Cancer 30A(3): 344-350

Olen O, Montgomery SM, Marcus C, Ekbom A, Ludvigsson JF (2009) Coeliac disease and body mass index: a study of two Swedish general population-based registers. Scand J Gastroenterol 44(10): $1198-1206$

Plaskon LA, Penson DF, Vaughan TL, Stanford JL (2003) Cigarette smoking and risk of prostate cancer in middle-aged men. Cancer Epidemiol Biomarkers Prev 12(7): 604-609

Rodriguez C, Freedland SJ, Deka A, Jacobs EJ, McCullough ML, Patel AV, Thun MJ, Calle EE (2007) Body mass index, weight change, and risk of prostate cancer in the Cancer Prevention Study II Nutrition Cohort. Cancer Epidemiol Biomarkers Prev 16(1): 63-69

Schmid HP, McNeal JE, Stamey TA (1993) Clinical observations on the doubling time of prostate cancer. Eur Urol 23(Suppl 2): 60-63

Shimizu H, Ross RK, Bernstein L, Yatani R, Henderson BE, Mack TM (1991) Cancers of the prostate and breast among Japanese and white immigrants in Los Angeles County. Br J Cancer 63(6): 963-966

Shu X, Ji J, Li X, Sundquist J, Sundquist K, Hemminki K (2010) Cancer risk among patients hospitalized for type 1 diabetes mellitus: a populationbased cohort study in Sweden. Diabet Med 27(7): $791-797$

Smyth DJ, Plagnol V, Walker NM, Cooper JD, Downes K, Yang JH, Howson JM, Stevens H, McManus R, Wijmenga C, Heap GA, Dubois PC, Clayton DG, Hunt KA, van Heel DA, Todd JA (2008) Shared and distinct genetic variants in type 1 diabetes and celiac disease. $N$ Engl J Med 359(26): $2767-2777$

Vazquez H, Smecuol E, Flores D, Mazure R, Pedreira S, Niveloni S, Maurino E, Bai JC (2001) Relation between cigarette smoking and celiac disease: evidence from a case-control study. Am J Gastroenterol 96(3): $798-802$

Wright ME, Chang SC, Schatzkin A, Albanes D, Kipnis V, Mouw T, Hurwitz P, Hollenbeck A, Leitzmann MF (2007) Prospective study of adiposity and weight change in relation to prostate cancer incidence and mortality. Cancer 109(4): 675-684

This work is published under the standard license to publish agreement. After 12 months the work will become freely available and the license terms will switch to a Creative Commons Attribution-NonCommercial-Share Alike 3.0 Unported License. 